\title{
PLANEJAMENTO FINANCEIRO: FUGINDO DAS DÍVIDAS
}

\author{
Claudir Olipio GRÄF${ }^{1}$ \\ Marleni GRÄF

\begin{abstract}
${ }^{1}$ Administrador formado pela Horus Faculdades, mestre em Economia pela Unisinos, Professor substituto da UFFS. vendas.cg@hotmail.com

${ }^{2}$ Universidade do Oeste de Santa Catarina. marleni.25@gmail.com
\end{abstract}

Recebido em: 25/10/2013 - Aprovado em: 15/12/2013 - Disponibilizado em: 15/01/2014

\begin{abstract}
Resumo: O artigo apresenta um maior conhecimento sobre a área de finanças pessoais, assunto esse, muitas vezes, não avaliado com cuidado pela população, porém de fundamental importância para a redução do endividamento da população brasileira. Estudos mostram que cada vez mais a população vem aumentando seu nível de endividamento, chegando a 43,99\% apenas com as instituições bancária, levando a observar que as famílias passam mais de cinco meses por ano trabalhando para pagar suas dívidas o que acarreta em dificuldade de crescimento financeiro familiar, onde as famílias estão sempre pagando suas dívidas, sem conseguir acumular riquezas, o que dificulta a ascensão financeira familiar, pois juntamente com as dívidas a serem pagar, encontram-se altas taxas de juros que corroem o poder de compra das famílias introduzindo certa dependência econômica das famílias para com o sistema financeiro. O que pode se perceber é que a população não está analisando suas alternativas financeiras e, muitas vezes, por falta de uma orientação adequada sobre o tema, acabam sendo seduzidas pelas campanhas publicitárias sem mesmo analisar suas condições financeiras pessoais no momento de tomar uma decisão de consumo.
\end{abstract}

Palavras chave: Planejamento. Educação. Finanças pessoais. Endividamento. Renda familiar.

Abstract: The paper presents a greater knowledge about the area of personal finances, a subject not often evaluated carefully by the population, but of fundamental importance to the reduction of debt of the Brazilian population. Studies show that, increasingly, the population has been increasing its level of indebtedness, reaching $43.99 \%$ only with the banking institutions, leading to note that families spend more than five months a year working to pay their debts, resulting in difficulty with growing the family financial, where families are always paying his debts, unable to accumulate wealth, which hinders the ascent family financial, because with the debts to be paid, are high interest rates that erode the power of household purchasing and introducing certain economic dependence of households to the financial system. What can be noticed is that the population is not analyzing your financial alternatives, and often a lack of adequate guidance on the issue, end up being seduced by advertising campaigns, without even analyzing your personal financial condition at the time of taking a decision about the consumption.

Keywords: Planning. Education. Personal Finances. Indebtedness. Family income.

\section{Introdução}

O Artigo é desenvolvido, buscando demonstrar como a educação financeira faz a diferença na vida das pessoas, para obter-se êxito em tal estudo, foi realizada uma pesquisa bibliográfica sobre o assunto, demonstrando a importância da educação financeira, e suas consequências quando da falta.
Esse estudo se faz importante para demonstrar que manter as finanças pessoais em dia não significa não comprar o que se deseja, mas sim planejar como e quando comprar. É possível fazer viagem de férias, comprar carro novo, ou fazer outros investimentos de alto custo sem comprometer as finanças pessoais, desde que esses investimentos sejam planejados. 
$\mathrm{O}$ artigo debate ainda a importância de se manter o controle das finanças pessoais, gerindo-as de forma similar a gestão aplicada ao ramo empresarial, que se apresenta eficaz e de extrema importância para a saúde financeira das empresas, já no lado pessoal, as finanças também necessitam de uma gestão responsável, porém muitas vezes ignorada por grande parte da população, o que leva a um preocupante índice de endividamento das famílias, que segundo dados do Banco Central chegou a $43,99 \%$ no primeiro trimestre do ano.

\section{Finanças pessoais.}

A administração financeira é estudada pelos cursos de administração e demais cursos como um conhecimento importante para a empresa, as empresas que não administram de forma adequada suas finanças dificilmente sobrevivem no mercado.

Groppelli e Nikbakht (2002) descrevem que a Administração financeira no ramo empresarial é uma área desafiadora, compensadora e estimulante, pois os administradores financeiros tem responsabilidade de planejar o futuro da organização.

$\mathrm{Da}$ mesma forma que as empresas precisam ter planejamento financeiro, as pessoas também precisam ter planejamento e controle de suas finanças e esse controle necessário não é estudado nas universidades, conscientização financeiras das pessoas e muitas vezes na própria casa esse assunto também não é tratado, pois quando os pais tem dificuldades em controlar seus gastos, como vão ensinar seus filhos?

O mercado através das campanhas de publicidade desperta nas pessoas o desejo de consumir, comprar para aumentar sua autoestima, porém quando chega o final do mês as pessoas estão sem dinheiro, endividadas e chegam ao ponto de não saber como se equilibrarem, pois gastam muito mais do que recebem de salário.

No mês de março deste ano, as famílias brasileiras atingiram um endividamento de $43,99 \%$, representando que quase metade de toda a renda anual está comprometida com as instituições financeiras, sendo este o mais alto índice, desde o início da medição pelo Banco Central em 2005, quando o endividamento o familiar estava em $18,39 \%$ de sua renda ${ }^{1}$.

Por esse motivo o equilíbrio financeiro se faz necessário, para que as pessoas deixem de consumir por impulso, comprando somente o que é necessário e conseguem pagar com o salário que recebem.

Para manter suas finanças pessoais em dia é necessário que as pessoas tenham planejamento financeiro. $\mathrm{O}$ planejamento financeiro é um processo em que as pessoas precisam administrar sua renda, seus investimentos, seu patrimônio e suas dívidas (FINANCENTER, 2013).

o mercado não faz campanhas para 
O planejamento financeiro não trata somente de gastar menos do que se ganha, também há necessidade de estabelecer objetivos financeiro para a vida, como por exemplo comprar uma casa, abrir um negócio próprio, viajar, ter filhos, enfim os vários desejos que as pessoas têm para seu futuro necessitam estar estabelecidos no presente para que possam se tornar realidade (FINANCENTER, 2013).

“O planejamento das finanças não visa apenas o sucesso financeiro, ele é relevante para o sucesso pessoal e profissional" (FINANCENTER, 2013).

Percebe-se que as pessoas são mais felizes quando tem suas finanças em dia, não pelo fato de dinheiro trazer felicidade, mas pelo fato de poder realizar seus projetos com mais facilidade, por ter planejado o investimento necessário para tal.

Pinheiro (2013) afirma que "a educação financeira pode ser definida como a habilidade que os indivíduos apresentam de fazer escolhas adequadas ao administrar suas finanças pessoais durante o ciclo de sua vida".

A educação Financeira pode ser entendida como uma forma na qual as pessoas melhoram sua compreensão sobre produtos e conceitos financeiros promovendo a habilidade e confiança necessárias para que o indivíduo se torne consciente dos riscos e benefícios para melhorar seu bem estar financeiro (PINHEIRO, 2013).

Pessoas não instruídas financeiramente tendem a ter dificuldades para administrar seus próprios recursos. É natural que essas pessoas desconheçam conceitos como juros, investimentos, taxas, entre outras relacionadas ao mundo das finanças. Sendo assim, pessoas com pouco conhecimento financeiro não sabem avaliar uma compra ou analisar o melhor investimento para seus recursos (SOUSA; TORRALVO, 2008).

Um exemplo é o uso de cartões de crédito. Com tanta facilidade e baixa instrução, há pessoas que preferem pagar a parcela mínima da fatura do cartão de crédito para não sacar recursos da poupança. Ou seja, investem seus recursos em uma aplicação de baixa remuneração e pagam juros altíssimos sobre gastos muitas vezes desnecessários, ou até mesmo tomam dinheiro emprestado à taxa de juros mais elevada entre as possíveis linhas de empréstimo (SOUSA; TORRALVO, 2008).

Atualmente as pessoas têm muitas facilidades para comprar, se não tem dinheiro, as lojas vendem parcelado, ou no cartão de crédito que por sua vez é uma ótima alternativa para quem sabe controlar o quanto pode gastar, as formas de obter crédito e financiamentos se tornaram tão fáceis que cada vez mais as pessoas buscam essas alternativas sem avaliar sua real necessidade.

Cerbasi (2012) afirma:

Se todos os brasileiros usassem crédito com inteligência e consciência, comparando alternativas para pagar menos [...] planejando suas finanças para honrar compromissos e pagando juros para enriquecer ou para preservar os cuidados com seu futuro, o crescimento econômico do país seria inevitável. 
Essa afirmativa comprova que é possível manter o próprio equilíbrio financeiro e dessa forma ainda contribuir para o crescimento econômico do país, fato que é desconhecido por muitas pessoas.

Cerbasi (2012) afirma que pode-se reverter o quadro da economia nacional quando as pessoas souberem planejar, fazer escolhas sustentáveis e conscientes de crédito. O lamentável é que essa realidade ainda está longe.

Não se pode culpar o mercado pelas formar erradas com que os consumidores se comportam, como já diziam Groppelli e Nikbakht (2002) o objetivo das empresas é a curto prazo gerar lucros e a longo prazo maximizar sua riqueza. Para que isso seja possível as empresas precisam vender seu produto ou serviço, sem necessidade de saber se o consumidor realmente tem necessidade de tal produto. Porém é possível que cada consumidor avalie a real necessidade e possibilidade de adquirir determinado produto, cabendo a cada um a decisão de consumo, não deixando com que as campanhas de publicidade faças as decisões de consumo pelos consumidores.

$$
\text { Savoia, Saito e Santana (2007) }
$$
descrevem que no Brasil as pessoas não tem apoio das autoridades quando o assunto é educação financeira, algumas instituições financeiras até tem essa preocupação, mas são minoria no país. Dessa forma a população acaba por não ter educação financeira adequada.
Mello (2010) afirma que há necessidade de inserir a educação financeira no dia a dia para demonstrar às pessoas o valor do dinheiro possibilitando a formação de patrimônio.

Não há como negar que a educação financeira é fundamental para a sociedade brasileira e torna-se de grande importância inseri-la no contexto político nacional visto que influencia diretamente nas decisões de indivíduos e famílias brasileiras (SAVOIA; SAITO; SANTANA, 2007).

Mandell (2005) apud Savoia, Saito e Santana (2007) destaca que a inserção da educação financeira nas escolas dos Estados Unidos ocasionou a propensão de poupar nos estudantes. O que auxiliou os estudantes nas suas decisões de compras atuais e futuras.

Pinheiro (2013) descreve que a educação financeira se faz importante em todas as fases da vida, na infância para compreender o valor do dinheiro, na juventude permite viver de forma independente, e na vida adulta permite a realização de grandes sonhos e o sustento da família.

Savoia, Saito e Santana (2007) descrevem resultados de várias pesquisas realizadas em todo o mundo em países que tem a educação financeira como currículo escolar e constatou que com a educação financeira as pessoas ficam mais seguras e felizes em suas decisões de compra. Já no Brasil não há pesquisas que relatam efeitos da 
educação financeira, até mesmo porque no Brasil não se tem o hábito dessa educação.

A administração das finanças pessoais é um assunto que deveria começar a ser discutido nas escolas brasileiras. Embora a educação financeira seja um processo trabalhoso, contínuo e complexo, é fundamental para que o ser humano entenda o mundo em que vive e os riscos do sistema financeiro. "Quando o indivíduo tem as finanças em ordem, ele toma decisões e enfrenta melhor as adversidades. E isso ajuda não só nos estudos, mas também nos aspectos familiares" (ROCHA, 2008).

Embora a mídia tenha se esforçado para fazer matérias didáticas sobre finanças pessoais e embora seja fácil encontrar informações sobre o assunto, as pessoas não estão preparadas para entendê-las. Anos atrás as famílias se reuniam e tentavam entender o mundo. Hoje, toda responsabilidade da educação foi transferida para a escola, porém a escola não tem condições de ensinar tudo, ela precisa, acima de tudo, preparar as pessoas para procurar oportunidades e não para procurar um emprego. A família precisa voltar a aprofundar suas ligações e criar vínculos com o sucesso, e ao professor cabe o papel de mediador (ROCHA, 2008).

Nos países desenvolvidos a educação financeira cabe às famílias. Às escolas cabe a função de reforçar a formação adquirida em casa. No Brasil, a educação financeira não está presente nem no universo familiar nem tampouco nas escolas. “Assim, a criança não aprende a lidar com dinheiro nem em casa, nem na escola. As consequências deste fato são determinantes para uma vida de oscilações econômicas, com graves repercussões tanto na vida do cidadão, quanto na do país" (D’AQUINO, 2007).

A educação financeira deveria iniciar dentro da família e ser complementada nas escolas, onde as pessoas poderiam aprofundar-se em conceitos mais específicos e receber um apoio na busca de oportunidades. Infelizmente, essa não é a realidade brasileira. A falta de educação financeira, conforme Sousa e Torralvo (2008) reflete uma não valorização do dinheiro acompanhada de um desperdício maior e desnecessário deste. Além disso, a falta de discernimento financeiro acaba influenciando outras áreas da vida social. Comportamentos agressivos e pessimistas, brigas e discussões na família podem estar associados a problemas financeiros.

Pinheiro (2013) destaca que "a carência de educação financeira expõe os agentes a riscos, o que acarreta danos não apenas às suas vidas, mas também à sociedade como um todo".

Apesar da falta de estudos nessa área as organizações públicas e privadas brasileiras não estão atentas à educação financeira da população, não há divulgações de informações sobre finanças pessoais para auxiliarem os brasileiros no gerenciamento de suas finanças (MELLO, 2010). 
Cerbasi (2003) destaca que a educação financeira é uma questão cultural, lembrando que os brasileiros são educados para consumir e não economizar, para serem aceitas em seu grupo social, as pessoas precisam ser bem vistas, isso inclui estarem bem vestidos, ter objetos da moda, tecnologia avançada entre outros.

A maioria das pessoas tem desejos de compra e o satisfazem imediatamente, não tem a consciência de que economizando poderão futuramente obter muito mais do que no momento em que vivem, porém não tiveram a educação financeira necessária para tomar uma atitude de economia (CERBASI, 2003).

Mello (2010) dispõe que é fundamental a realização de pesquisas sobre o assunto a fim de fornecer informações à população para que esses possam utilizar de forma consciente e em seu favor o sistema financeiro brasileiro e não ser vítimas dele.

Conforme Sousa e Torralvo (2008) é comum o aumento do consumo quando se eleva a renda. Muitas pessoas, assim que conseguem uma promoção e começam a ganhar mais, mudam seu padrão de vida, compram uma casa melhor, um carro novo, passam a usar roupas de marcas importadas, a fazer viagens para o exterior e não abrem mão de obter o ultimo lançamento dos produtos de maior preferência.

Esse comportamento reflete certa falta de planejamento financeiro. Investe-se muito no conforto e na realização de desejos momentâneos, mas a falta de conhecimento financeiro faz com que as pessoas não percebam que a compra de um carro novo, por exemplo, acarretará perda do dinheiro com a desvalorização do automóvel e diversas despesas fixas como: seguro, IPVA, estacionamento e manutenção. Conforme Cerbasi (2003), o que muitos pensam ser um investimento é na verdade um custo. Investimento é quando se adquire algo, para, em determinado tempo, obter lucro, seja na compra de um imóvel ou em uma aplicação financeira. Investimento sempre é feito com o intuito de ganhar dinheiro.

O ideal seria utilizar os ganhos extras, com o aumento da renda, para fazer investimentos. É claro que não se deve privar de bens e serviços que trazem conforto e que sejam motivo de desejo. Mas, ao contrário, com uma reflexão maior sobre a tomada de decisão com relação ao consumo e a com a utilização de um planejamento financeiro, é possível atingir objetivos estipulados sem desperdiçar recursos, nem comprometer seu futuro financeiro (SOUSA; TORRALVO, 2008).

As recompensas trazidas pela disciplina financeira são resumidas por Souza e Torralvo (2008)

Com um planejamento pessoal persistente e bem-feito, a árdua tarefa de manter a disciplina financeira é muito facilitada, permitindo a realização dos desejos de consumo, uma maior segurança para enfrentar situações inesperadas, e a formação de reservas para garantir a necessária segurança pessoal e a indispensável tranquilidade e o desfrute de uma boa renda na velhice. 
Pinheiro (2013) destaca que o setor de serviços financeiros registra uma rápida evolução. A inovação e a globalização fazem com que os cidadãos tenham acesso a um leque crescente de produtos e serviços destinados a satisfazer diferentes circunstâncias e necessidades. Porém, para muitos indivíduos estes serviços são complexos e seu desempenho futuro é de difícil avaliação, o que pode resultar na contratação de um serviço que não atende a expectativa do indivíduo, ou até mesmo, leválo a ser vítima de fraudes.

Mesmo da diversificação de produtos ter seus benefícios para os consumidores finais, por proporcionarem maior poder de escolha, é preciso que se mantenha um maior nível de conhecimento para que a população tenha a capacidade de diferenciar os investimentos feitos, as reais necessidades de consumo e as formas mais viáveis de pagamento das compras a serem efetuadas, para se evitar a excessiva tomada de empréstimos e parcelamento de compras o que acaba acarretando no aumento da inadimplência. $\mathrm{O}$ desconhecimento financeiro pode levar as pessoas a serem vítimas de uma série de praticas enganosas utilizadas pelo mercado para estimular o consumo e aumentar a lucratividade (PINHEIRO, 2013).

Cerbasi (2003) destaca que é possível ficar rico sem grandes dificuldades, basta ter disciplina e visão de longo prazo. Algumas pessoas optam pela riqueza através de investimentos de risco, esses investimentos trazem a riqueza, mais rápida, mas também podem tirá-la rapidamente, outras pessoas optam pela segurança financeira, é um caminho mais longo, com o futuro definido a longo prazo.

Mello (2010) afirma que não é a quantidade de dinheiro que soluciona os problemas financeiros das pessoas, essa situação é percebida pelas pessoas que de alguma forma ficaram milionárias do dia para a noite e depois com a mesma velocidade voltaram à situação anterior. Frankenberg (1999) apud Mello (2010) afirma que essa situação acontece por falta de educação financeira, o que demonstra que não é a quantidade de dinheiro que muda a vida de alguém, mas sim como trabalhar com essa quantidade.

O grande diferencial das pessoas que possuem um bom controle de suas finanças pessoais está na forma com que estas encaram o dinheiro, e o segredo de se manter o equilíbrio financeiro pessoal inicia com o controle das finanças, qual a renda mensal disponível, para então avaliar quais as principais necessidades a serem sanadas e a partir daí, manter uma educação contínua de investimento, para que as reservas obtidas e investidas passem a produzir renda. Conforme Kiyosaki, Fleming e Kiyosaki (2012) afirmam: "é uma questão de seus valores essenciais", nos quais o equilíbrio nas finanças pessoais não depende da quantidade de horas trabalhadas diariamente e sim das 
decisões que são tomadas diariamente com relação ao fluxo de caixa pessoal.

\section{Considerações finais}

Através do presente estudo percebe-se que a educação financeira no Brasil ainda é pouco compreendida e são poucas as pessoas que tem acesso aos benefícios que essa educação pode trazer para a população.

Enquanto inúmeras pessoas gastam muito mais do que recebem de salário e não buscam alternativas de ampliar seus rendimentos mensais a educação financeira mostra que o primeiro passo para encontrar a estabilidade financeira é justamente gastar menos do que ganha.

Por esse motivo percebe-se que a falta de educação financeira faz com que as pessoas consumam por impulso ou desejo sem analisar a real necessidade e depois se tornam infelizes por não conseguir se estabilizar financeiramente.

Acredita-se que o assunto educação financeira deva ser implementado nas escolas brasileiras, tomando por base outros países que possuem essa educação, para que a população possa estar consciente de que existem inúmeras formas de economizar na atualidade para poder usufruir de diversos benefícios financeiros no futuro.

Os dados do banco central revelam que a população realmente não está analisando as alternativas financeiras e estão se deixando seduzir pelas campanhas publicitárias que visam o consumo desenfreado, endividando cada vez mais as famílias e freando assim o crescimento econômico do país.

\section{Notas:}

${ }^{1}$ Dados extraídos do site www.oglobo.com.br

\section{Referências Bibliográficas}

CERBASI, G. Crédito inteligente. 2012.

Disponível em

$<$ http://www.maisdinheiro.com.br/artigos/3/3/ credito-inteligente>. Acesso em 16 maio 2013.

\section{Dinheiro: os segredos de quem}

tem: como conquistar e manter sua independência financeira. 13 e.d. São Paulo: Gente, 2003. Disponível em $<$ http://books.google.com.br/books?hl=pt$\mathrm{BR} \& \mathrm{lr}=\& \mathrm{id}=\mathrm{mm}-$

kYqmIJ9kC\&oi=fnd\&pg=PA23\&dq=related: 02QwvB4fwOcJ:scholar.google.com/\&ots=Ti tmjXGPQi\&sig=HSxzyWmykSPpvx8ANMH OYJ4PLrc\# $\mathrm{v}=$ onepage $\& \mathrm{q} \& \mathrm{f}=$ false $>$ acesso em 18 maio 2013.

. O futuro começa hoje. Você S/A,

São Paulo, 110 ed, p. 72-73,ago. 2007.

D’AQUINO, Cássia. O que é educação financeira. Disponível em:

$<$ http://www.educfinanceira.com.br/conteudo. asp?id_conteudo=2> Acesso em: 18 mai. 2013.

FINANCENTER. Planejamento de suas finanças. Disponível em $<$ http://financenter.terra.com.br/index.cfm/Fu seaction/Secao/Id_Secao/435.html > acesso em 16 maio 2013.

GIL, Antônio Carlos. Como elaborar projetos de pesquisa. 4. ed. São Paulo: Atlas, 2002. 
GROPPELLI, A. A.; NIKBAKHT, E.

Administração financeira. 2. ed. São Paulo:

Saraiva, 2002.

KIYOSAKI, R.T.; FLEMING, J.;

KIYOSAKI, KIN. O negócio do século XXI.

5. ed. Rio de Janeiro: Elsevier, 2012.

MELLO, R. M. Gestão financeira pessoal de funcionários com emprego estável funcionários do banco X S.A. Porto Alegre, 2010. Disponível em

<http://www.lume.ufrgs.br/bitstream/handle/1 0183/36702/000792907.pdf?sequence $=1>$ acesso em 20 maio 2013.

PINHEIRO, R. P. Educação Financeira e previdenciária, a nova fronteira dos fundos de pensão. Disponível em

<http://www.mps.gov.br/arquivos/office/3_09 0420-113416-244.pdf $>$ acesso em 21 maio 2013.

ROCHA, Ricardo Humberto. Educação financeira em pauta. fev. 2008. Disponível em: <http://financenter.com.br/>. Acesso em: 17 maio 2013.

SAVOIA, J. R. F.; SAITO, A. T.;

SANTANA, F. A. Paradigmas da educação

financeira no Brasil. Rio de Janeiro, nov.;

dez. 2007. Disponível em

$<$ http://www.scielo.br/pdf/rap/v41n6/06.pdf>. Acesso em 17 maio 2013.

SOUSA, A.F.; TORRALVO, C.F. Aprenda a administrar o próprio dinheiro. São Paulo: Editora Saraiva, 2008. 160 p.

VALENTE, G. Endividamento das famílias bate recorde: $\mathbf{4 3 , 9 9 \%}$ da renda. Maio 2013 . Disponível em:

<http://oglobo.globo.com/economia/endivida mento-das-familias-bate-recorde-4399-darenda-8516655>. Acesso em 23 jul 2013. 